\title{
Cancer-Related Alopecia: From Etiologies to Global Management
}

\author{
Stanislas Quesada ${ }^{1,2,3, * \mathbb{C}}$, Alexandre Guichard ${ }^{4} \mathbb{D}$ and Frédéric Fiteni ${ }^{2,3,5}$ \\ 1 Institut Régional du Cancer de Montpellier, 34090 Montpellier, France \\ 2 Medical Oncology Department, University Hospital, 30900 Nîmes, France; Frederic.FITENI@chu-nimes.fr \\ 3 Faculty of Medicine, University of Montpellier, 34090 Montpellier, France \\ 4 Legacy Healthcare Switzerland SA, 1066 Epalinges, Switzerland; guichard.alexandre@gmail.com \\ 5 UMR INSERM IDESP-Desbrest Institute of Epidemiology and Public Health, University of Montpellier, \\ 34090 Montpellier, France \\ * Correspondence: stanislas.quesada@icm.unicancer.fr
}

Citation: Quesada, S.; Guichard, A.; Fiteni, F. Cancer-Related Alopecia:

From Etiologies to Global

Management. Cancers 2021, 13, 5556.

https://doi.org/10.3390/

cancers13215556

Academic Editor: Marco

Cesare Maltoni

Received: 7 September 2021

Accepted: 3 November 2021

Published: 5 November 2021

Publisher's Note: MDPI stays neutral with regard to jurisdictional claims in published maps and institutional affiliations.

Copyright: (c) 2021 by the authors. Licensee MDPI, Basel, Switzerland. This article is an open access article distributed under the terms and conditions of the Creative Commons Attribution (CC BY) license (https:/ / creativecommons.org/licenses/by/ $4.0 /)$.
Simple Summary: Although it does not represent a condition that threatens the life of patients, alopecia nevertheless has an essential impact on the quality of life of patients, particularly in terms of the psychological and social aspects. Indeed, while it has long been considered an acceptable side effect in the management of patients, the progressive emergence of a patient-centered approach coupled with a better knowledge of the pathophysiological processes involved has led to a better consideration of alopecia, both on the preventive and palliative sides. Thus, cancerous alopecia can be multifactorial: iatrogenic (in particular via conventional chemotherapy), induced by a vita$\mathrm{min} /$ nutritional deficiency, or even caused by the disease itself. In this state-of-the-art review, we therefore cover alopecia in an exhaustive manner by considering the different mechanisms involved and their frequency as well as the various therapies offered.

Abstract: Alopecia represents a multifaceted challenge with distinct etiologies and consequences. Transposed to the world of oncology, different types of alopecia and molecular pathways have been characterized, allowing a better understanding of the underlying mechanisms. In patients with cancer, alopecia can be iatrogenic (i.e., due to conventional chemotherapies, endocrine therapies, targeted therapies, immunotherapies, radiotherapy and surgery) or a direct consequence of the disease itself (e.g., malnutrition, scalp metastases and paraneoplastic syndromes). Identification of the actual incriminated mechanism(s) is therefore essential in order to deliver appropriate supportive care, whether preventive or curative. On the preventive side, the last few years have seen the advent of the automated cooling cap, a prophylactic approach supported by several randomized clinical trials. On the curative side, although the treatments currently available are limited, several promising therapeutic approaches are under development. Appropriate alopecia management is essential, particularly regarding its psychological repercussions with significant consequences on the quality of life of patients and their family and with a potential impact on treatment compliance.

Keywords: alopecia; supportive care; psycho-oncology; quality of life

\section{Introduction}

Alopecia, which is defined as a decrease in hair density, exhibits a wide range of features. Indeed, it may be localized, diffuse or total, acute or chronic, sudden or gradual, reversible or permanent. Alopecia might be considered as a common symptom to several pathologies with varied etiologies (e.g., immunological, inflammatory and infectious). In addition, alopecia can be the sentinel sign of systemic diseases: endocrine (e.g., thyroid dysfunction), autoimmune (e.g., systemic lupus erythematosus), psychiatric (e.g., trichotillomania) or infectious. Alopecia can be classified into three classes: non-scarring 
(such as androgenetic alopecia-AGA, which is the most common alopecia), scarring (with destruction of the hair follicle) and congenital alopecia [1].

Understanding hair alterations requires knowledge of its physiology. Briefly, hair is a complex mini-organism with rapid renewal, a dense vascular network and immune privilege. The hair's life cycle is schematically divided into four phases: anagen (4-6 years growth), catagen (3 weeks with massive apoptosis), telogen (3 month resting followed by expulsion) and kenogen (2-12 months latency). Hair follicles are asynchronous in humans, with $\approx 85 \%$ of anagen hair, $\approx 1 \%$ of catagen hair and $\approx 15 \%$ of telogen hair. Hair loss is considered as pathological when it represents more than 150 hairs per day. Importantly, hair loss is not necessarily accompanied by a visible decrease in hair density. Of note, effluvium corresponds to a sudden, abundant and diffuse hair loss, which can be acute or chronic and affect anagen or telogen hair [1].

Although it is not life threatening, alopecia represents one of the most important parameters affecting the quality of life (QoL) of patients with cancers, particularly in terms of the psychological and social aspects [2-4]. Notably, caregivers tend to underestimate the impact of alopecia on patients [5]. Indeed, while it has long been considered an acceptable side effect in the management of patients, the increasing number of cancer survivors coupled with a better knowledge of the pathophysiological processes involved has led to a better consideration of alopecia, both on the preventive and palliative sides.

To our knowledge, although there are several excellent reviews focused on a specific aspect of cancer-related alopecia (e.g., reviews assessing mechanisms involved in hair disorders in cancer, notably through anticancer therapies), there is not currently an integrative review that could help physicians and healthcare providers involved in the supportive care in cancers in gaining a global approach.

As such, the scope of this review is to provide physicians with a state-of-the-art and clinical practice-driven review, assessing in a comprehensive manner the distinct mechanisms involved in cancer-related alopecia, their respective frequencies and the current and future treatment approaches.

\section{Cancer-Related Alopecia: Mechanisms and Epidemiology}

\subsection{Classification and Diagnosis}

In spite of being a common side effect of many cancer therapies, its clinical presentations, frequencies and underlying mechanisms are plural and mainly related to the type of treatment used, without distinction of gender or age. Clinically, alopecia can be accompanied by dysesthesia, pruritus and dryness of the scalp [6]. It is not restricted to the scalp and can therefore affect other body hair, such as the eyebrows, eyelashes and axillo-pubic hair. Table 1 shows the main characteristics of these attacks according to the treatment used [7-14].

Schematically, it is possible to classify antineoplastic-induced alopecia (ANIA) into three groups (which can be overlapping) according to their mechanism: follicle destruction (mainly chemotherapy and radiotherapy), follicle miniaturization (mainly endocrine and targeted therapies) and hair cycle blockage (mainly immunotherapy). By knowing the exact mechanism of action, the clinician is able to adjust the management of alopecia.

Alopecia diagnosis is based on both anamnesis and clinical presentation, which becomes visible when hair density loss is greater than $50 \%$. ANIA and other hair disorders share common clinical patterns. A macroscopic examination with dermoscopy (called "trichoscopy" when applied to the scalp) represents an important tool of diagnosis and prognosis, allowing a finer assessment of hair density, thickness and hair shaft anomalies. In addition, the trichogram, a semi-invasive quantitative technique consisting of a microscopic analysis of a plucked hair's bulb, allows the quantification of anagen and telogen hairs, which may be relevant for ANIA diagnosis and to perform differential diagnosis [15]. 
Table 1. Main characteristics of hair disorders according to the anticancer therapies used (adapted from references [7-14]).

\begin{tabular}{|c|c|c|c|c|c|}
\hline $\begin{array}{l}\text { Treatment } \\
\text { Type }\end{array}$ & $\begin{array}{c}\text { Clinical } \\
\text { Topography }\end{array}$ & $\begin{array}{l}\text { Main Incriminated } \\
\text { Mechanism(s) }\end{array}$ & Time to Onset & Reversibility & $\begin{array}{l}\text { Frequency (\%) } \\
\text { and Range ([]) }\end{array}$ \\
\hline Chemotherapies & $\begin{array}{c}\text { Diffuse } \\
\text { and }+/- \text { total }\end{array}$ & $\begin{array}{l}\text { Cell division blockage } \\
\text { and apoptosis } \\
\text { Destruction of the } \\
\text { follicle }\end{array}$ & $\begin{array}{l}2-3 \text { weeks } \\
\text { from start }\end{array}$ & $\begin{array}{c}\text { Average: } 3-6 \\
\text { months } \\
\text { post-treatment } \\
\text { Irreversible (with } \\
\text { certain regimens) }\end{array}$ & $\begin{array}{c}\approx 65 \\
{[<10-100]}\end{array}$ \\
\hline $\begin{array}{l}\text { Endocrine } \\
\text { therapies }\end{array}$ & $\begin{array}{c}\text { Hair thinning } \\
\text { AGA-like pattern }\end{array}$ & $\begin{array}{l}\text { Miniaturization of the } \\
\text { follicle }\end{array}$ & 1-91 months & Not systematic & $\begin{array}{c}\approx 5 \\
{[0-25]}\end{array}$ \\
\hline Targeted therapies & $\begin{array}{c}\text { Very variable } \\
\text { (target dependent) }\end{array}$ & $\begin{array}{l}\text { Miniaturization of the } \\
\text { follicle } \\
(+/- \text { destruction })\end{array}$ & Very variable & $\begin{array}{l}\text { Possible even } \\
\text { during treatment } \\
\text { Irreversible with } \\
\text { some molecules }\end{array}$ & $\underset{[2-60]}{\approx 15}$ \\
\hline $\begin{array}{l}\text { Radiotherapy } \\
\qquad(<43 \mathrm{~Gy})\end{array}$ & $\begin{array}{l}\text { Depending on the } \\
\text { radiation field }\end{array}$ & $\begin{array}{l}\text { Destruction of the } \\
\text { follicle }\end{array}$ & $\begin{array}{l}1-3 \text { weeks } \\
\text { from start }\end{array}$ & $\begin{array}{l}\text { Average: } 2-4 \\
\text { months } \\
\text { post-irradiation }\end{array}$ & $\approx 75-100$ \\
\hline $\begin{array}{l}\text { Radiotherapy } \\
\qquad(\geq 43 \mathrm{~Gy})\end{array}$ & $\begin{array}{l}\text { Depending on the } \\
\text { radiation field }\end{array}$ & $\begin{array}{l}\text { Destruction of the } \\
\text { follicle }\end{array}$ & $\approx 100$ weeks & $\begin{array}{l}\text { No (scaring } \\
\text { alopecia) }\end{array}$ & $\approx 75-100$ \\
\hline Immunotherapies & Variable & $\begin{array}{l}\text { Cycle blockage and } \\
\text { dysimmunity }\end{array}$ & Variable & Variable & $\approx 1-2$ \\
\hline
\end{tabular}

The severity of ANIA is mainly scored with the Common Terminology Criteria for Adverse Events (CTCAE) classification and the Severity of Alopecia Tool (SALT) score (Table 2) [16,17]. The SALT score, defined by Olsen and colleagues, is expressed as a percentage of hair loss and can be used either as a continuous or as a categorical variable (Figure 1).

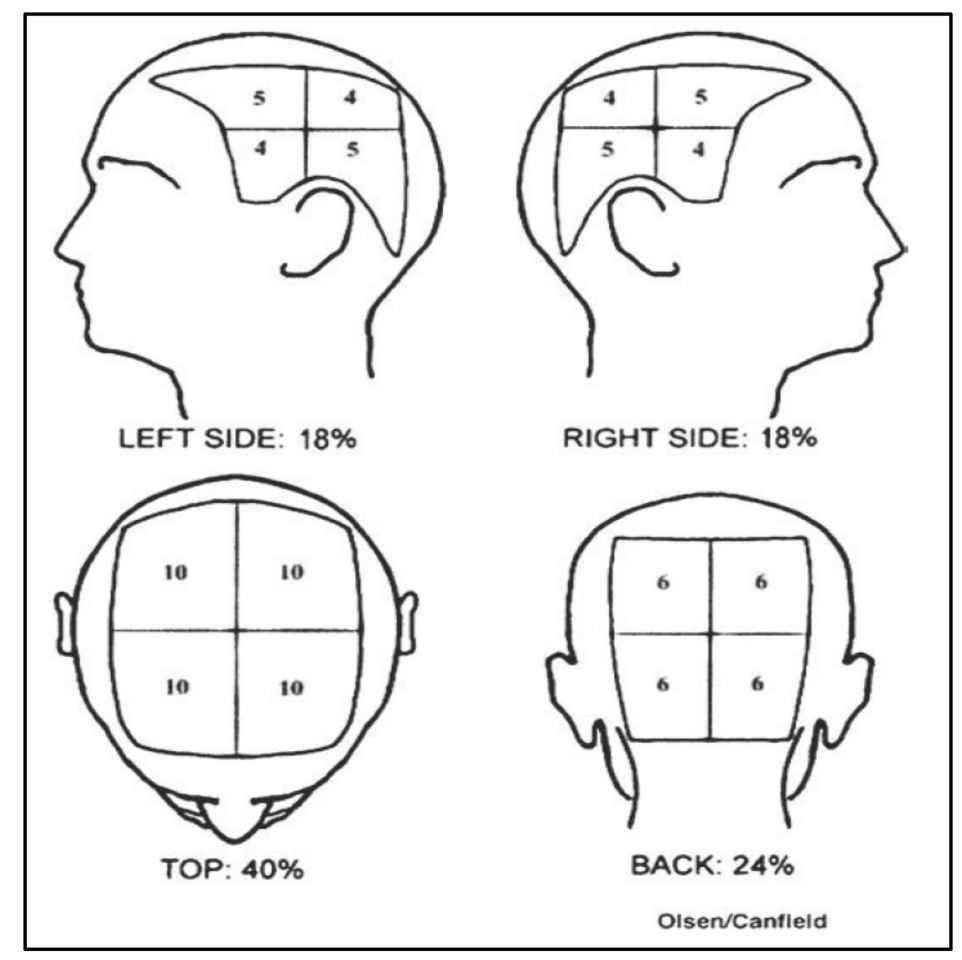

Figure 1. Severity of Alopecia Tool (SALT) score scheme (adapted from reference [16]). 
Table 2. Comparison of SALT, Olsen and CTCAE v5.0 scores to assess the severity of chemotherapyinduced alopecia (adapted from references $[16,17]$ ).

\begin{tabular}{cccccccc}
\hline Clinical Aspect & Absent & Slight & \multicolumn{2}{c}{ Moderate } & \multicolumn{2}{c}{ Severe } & Total \\
\hline SALT hair loss $(\%)$ & 0 & $1-24$ & $25-49$ & $50-74$ & $75-95$ & $96-99$ & 100 \\
\hline Olsen grades & 0 & 1 & 2 & 3 & $4 \mathrm{a}$ & $4 \mathrm{~b}$ & 5 \\
\hline CTCAE v5.0 grades & 0 & \multicolumn{2}{c}{1} & & & \\
\hline
\end{tabular}

CTCAE in its version 5.0 defines two grades of severity. Grade 1 refers to hair loss of $<50 \%$, which is not obvious from a distance but only on close inspection, while grade 2 ties in with hair loss of $\geq 50 \%$ normal for that individual, which is readily apparent to others. While grade 1 can be hidden with a different hairstyle, grade 2 alopecia requires a wig if the patient desires to completely camouflage the disorder; furthermore, grade 2 alopecia is likely to lead to an impact on QoL. As such, QoL needs to be evaluated, notably in the context of severe and/or persistent alopecia. Two auto-questionnaires assessing the psychological distress induced by alopecia have been developed: the Chemotherapy-Induced Alopecia Distress Scale (directly assessing PDIA) and the Hairdex assessing alopecia-related QoL [2,18]. Importantly, the EORTC QLQ-BR45 includes an item on alopecia (item 34: "Have you been bothered by hair loss?") [19].

\subsection{Chemotherapy}

In spite of a frequency of $\approx 65 \%$ (all chemotherapy protocols combined) and the significant impact on patients' lives, research on chemotherapy-induced alopecia (CIA) has remained elusive until recently [20]. CIA appears sub-acutely quickly after the chemotherapy protocol initiation and turns maximal within a few weeks. After chemotherapy, hair growth will resume a normal rhythm within 3 months and normally reach an aesthetically suitable result at 6 months. Predominance in frontal and occipital regions is classically observed [16]. Molecularly, several pathways have been characterized, eventually leading to a massive apoptosis [21]. The mechanism is mainly an anagen effluvium, although telogen effluvium may also be observed [22].

The main predictive factor of CIA is the chemotherapy class (Table 3): alkylating agents, anthracyclines, taxanes and etoposide are the ones with the most common and severe effects $[10,11]$. Conversely, some molecules infrequently cause CIA; notably, molecules such as fluorouracil and methotrexate cause more patchy alopecia. Beyond the therapeutic class, various predictive factors are known: polychemotherapy regimen and dosage, concomitant anticancer treatment, nutritional and hormonal statuses and the presence of an underlying AGA [23]. Furthermore, a CIA risk stratification based on genomics is emerging, which could pave the way for better identification of high-risk patients in order to provide them with appropriate supportive care [24].

Table 3. Main chemotherapy molecules used against solid tumors and their corresponding frequency of alopecia (adapted from references $[10,11]$ ).

\begin{tabular}{|c|c|}
\hline Molecule (Class) & $\begin{array}{l}\text { All-Grade Estimated } \\
\text { Frequency }(\%)\end{array}$ \\
\hline Daunorubicin, doxorubicin, epirubicin (TI2) & \multirow{3}{*}{$\approx 80-100$} \\
\hline Docetaxel, paclitaxel (taxanes) & \\
\hline High-dose cyclophosphamide (AA) & \\
\hline Etoposide, Idarubicin (TI2) & \multirow{2}{*}{$\approx 40-60$} \\
\hline Intravenous topotecan, irinotecan (TI1) & \\
\hline
\end{tabular}


Table 3. Cont.

\begin{tabular}{cc}
\hline Molecule (Class) & $\begin{array}{c}\text { All-Grade Estimated } \\
\text { Frequency (\%) }\end{array}$ \\
\hline Bleomycin (CA) & $\approx 10-30$ \\
\hline Vinblastine, vincristine, vinorelbine (PA) & $<10$ \\
\hline 5-Fluorouracil, gemcitabine, methotrexate (AM) & \\
\hline Capecitabine (AM) & \\
Nota bene: frequencies are given for monotherapies and may be susceptible to variation depending on the \\
lating agent; AM = antimetabolite; CA = cytostatic antibiotic; PA = periwinkle alkaloids; PS = platinum salts; \\
T11 = type 1 topoisomerase inhibitor; T12 = type 2 topoisomerase inhibitor.
\end{tabular}

\subsection{Focus on Persistent CIA ( $p C I A)$}

Although classically considered as a temporary mechanism, several studies have shown that CIA might be persistent $[10,20,25]$. Initially described in hematology through allograft conditioning before bone marrow transplant [26], pCIA was later reported with solid tumors [27]. This latter discovery is manifested by a lesser knowledge of pCIA by oncologists compared to dermatologists [28]. pCIA is defined by the presence of alopecia beyond 6 months after chemotherapy completion. It can exhibit various clinical aspects: mostly diffuse and non-scarring ( $\approx 50 \%$ of cases), with possible scarring involvement.

Histologically, destruction of the follicular epithelial stem cell pool and follicular miniaturization are the main suspected mechanisms [25]. Actually, this is not an uncommon phenomenon, especially in patients treated for breast cancer $(\mathrm{BC})$ with taxane-based protocols [11]. Indeed, a prospective study has shown that $\mathrm{BC}$ patients treated with taxanes exhibited pCIA in $\approx 40 \%$ at 6 months, with persistence at 3 years [29]. These recent data reinforce previous observations, both retrospectively and prospectively [11].

Furthermore, pCIA also exhibits modifications in hair quality: indeed, it has been estimated that up to $75 \%$ of patients with pCIA still had hair thinning at 3 years postchemotherapy [30]. Notably, an association has recently been shown between a regulatory portion of the $A B C B 1$ gene and pCIA in patients with $B C$ treated with taxane-based chemotherapy [31]. Specific attention should be given after bone marrow transplant pCIA in pediatric oncology, where a frequency of $\approx 20 \%$ has been reported [32].

\subsection{Targeted Therapies (TTs)}

TTs cover very different mechanisms of action and targets and their impact on alopecia mainly depends on the molecular target(s). TT-induced alopecia (TIA) confirms the necessary activation of several signaling pathways, such as $S H H, E G F R$ and VEGF, in hair physiology [1].

Way different from CIA, TIAs exhibit specific profiles and evolutions [12]. Indeed, TIA does not appear suddenly and can regress through treatment course, with a whole range of hair modifications: texture, density, color and renewal rate [10,13]. According to a 2015 meta-analysis, TIA affects $\approx 15 \%$ of patients, with a molecule-dependent high variability (Table 4) [14].

Some molecules need to be outlined. Importantly, vismodegib (an SHH inhibitor) has the highest TIA rate, with an estimated frequency of $\approx 60 \%$; furthermore, cases of persistent TIA have been reported [33,34]. Anti-EGFR molecules present a certain risk of non-scarring alopecia, sometimes completed with a scarring pattern as a consequence of the iatrogenic anti-EGFR facial papulo-pustulosis. Furthermore, it should be noted that the hair has a dry, brittle and curly appearance; in addition, patients show characteristic hypertrichosis and trichomegaly [13]. BRAF inhibitors lead to initial alopecia in $\approx 20 \%$ of patients, although hair regrowth may occur despite continued treatment [35]. Notably, while the use of trametinib (MEK inhibitor) leads to alopecia in about 13\% of cases, dual 
BRAF/MEK inhibition with vemurafenib/cobimetinib or dabrafenib/trametinib leads to alopecia in $13 \%$ and $6 \%$ of cases, respectively $[13,14]$.

Table 4. Main * targeted therapy classes used against solid tumors and their corresponding risk of alopecia (adapted from references [10,12-14]).

\begin{tabular}{|c|c|}
\hline Molecule (Class) & $\begin{array}{l}\text { All-Grade Estimated } \\
\text { Frequency }(\%)\end{array}$ \\
\hline SMOi (vismodegib specifically) & 60 \\
\hline Mul-I (e.g., sorafenib, regorafenib) & $25-30$ \\
\hline BRAFi (e.g., dabrafenib, vemurafenib) & $20-25$ \\
\hline EGFRi (e.g., afatinib, erlotinib) & \multirow{6}{*}{$5-15$} \\
\hline VEGFRi (e.g., axitinib, cabozantinib, pazopanib, sunitinib) & \\
\hline Anti-VEGF (bevacizumab) & \\
\hline Anti-EGFR (e.g., cetuximab) & \\
\hline ALKi (e.g., crizotinib) & \\
\hline MEKi (e.g., trametinib) & \\
\hline 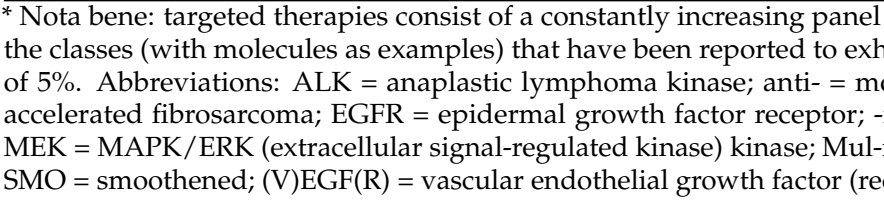 & $\begin{array}{l}\text { cules; thus, only listed her } \\
\text { ecia with a minimal frequ } \\
\text { l antibody; BRAF = B-ra } \\
\text { bitor; HER2 = human EG } \\
\text {-target protein kinase inhi }\end{array}$ \\
\hline
\end{tabular}

Interestingly, a phase 2 study evaluating bevacizumab monotherapy in patients with angiosarcoma reported a $\approx 10 \%$ incidence of alopecia, although this molecule is classically considered as not causative of alopecia [36]. With the "multi-targeted" protein kinase inhibitors sorafenib and regorafenib, the risk of alopecia should be considered, since frequencies of $25-30 \%$ have been reported [14,37]. Concerning emerging PARP inhibitors, no specific TIA has been reported to date [10].

\subsection{Endocrine Therapies (ETs)}

ET-induced alopecia (EIA) has mainly been described in the context of hormone receptor-positive $\mathrm{BC}$; indeed, the high prevalence of $\mathrm{BC}$ and the ET prescription length led to a fine characterization of this toxicity. Molecularly and clinically, EIA emerges in a different way, since it appears progressively and exhibits an AGA-like pattern [8]. The EIA overall incidence-assessed via a large meta-analysis-is $\approx 5 \%$, with significant variation depending on the therapeutic class(es) used (Table 5) [38]. Notably, total alopecia has been described in patients treated with tamoxifen [39]. Importantly, EIA can be a vector of non-compliance; indeed, it has been reported that $8 \%$ of patients stopped taking aromatase inhibitors because of EIA [40]. Notably, CDK4/6 inhibitors (used concomitantly with ET in BC) seem to potentiate EIA [41,42]. In the context of prostate cancer, none of the androgen deprivation therapies have been associated with EIA to date [9]. 
Table 5. Main endocrine therapies used against solid tumors and their corresponding frequency of alopecia (adapted from references [8-10]).

\begin{tabular}{|c|c|}
\hline Molecule (Class) & $\begin{array}{l}\text { All-Grade Estimated } \\
\text { Frequency }(\%)\end{array}$ \\
\hline All types of endocrine therapies & $\simeq 5 \%$ \\
\hline All types of endocrine therapies * & $\simeq 10 \%$ \\
\hline Letrozole (AI) + ribociclib (CDK4/6i) & $\simeq 33 \%$ \\
\hline Anastrozole $(\mathrm{AI})+$ gosereline $(\mathrm{aGnRH})$ & $\simeq 25 \%$ \\
\hline Letrozole $(\mathrm{AI})+$ palbociclib $(\mathrm{CDK} 4 / 6 \mathrm{i})$ & $\simeq 22 \%$ \\
\hline Fulvestrant (AE) + palbociclib (CDK4/6i) & $\simeq 15 \%$ \\
\hline Tamoxifen (SERM) then anastrozole (AI) & $\simeq 15 \%$ \\
\hline Tamoxifen (SERM) & $\simeq 10 \%$ \\
\hline Leuproreline (aGnRH) & $\simeq 10 \%$ \\
\hline Exemestane (AI) + aminoglutethimide & $\simeq 10 \%$ \\
\hline $\mathrm{AI}+$ fulvestrant $(\mathrm{AE})$ & $\simeq 8 \%$ \\
\hline Fulvestrant (AE) & $\simeq 2 \%$ \\
\hline Anastrozole, letrozole, exemestane (AI) & $\simeq 2 \%$ \\
\hline $\begin{array}{l}\text { Flutamide, bicalutamide, nilutamide, abiraterone, enzalutamide } \\
\text { (ADT) }\end{array}$ & $\leq 1 \%$ \\
\hline
\end{tabular}

\subsection{Radiotherapy (RT)}

Radiation-induced alopecia (RIA) has to be considered in two situations: central nervous system primary tumors and brain metastases. Apart from stereotactic RT, the classical treatment of brain metastases is the "pan-encephalic" RT (PERT) protocol. Historical studies have determined threshold doses per fraction: 0.75-2 Gy for temporary depilation and 8-16 Gy for hair follicle sterilization. Mechanistically, RIA consists of an anagen effluvium. Numerous predictive factors of RIA have been characterized: doses (per fraction and total), the type of ionizing radiations (photons vs. protons), the surface and volume of irradiation, concomitant treatment, hair capital and the genetic constitution of the patient [7].

RIA appearance is relatively abrupt and occurs within 1-3 weeks after treatment initiation. It concerns $75-100 \%$ of PERT-treated patients (since the dose per fraction is $>2$ Gy) with a regrowth around 2-4 months post-protocol [43].

Persistent RIA (pRIA) is defined as the presence of alopecia over 6 months post-RT; it is estimated to occur in $60 \%$ of PERT-treated patients, notably through scarring alopecia. Different predictive irradiation thresholds have been proposed: from $\approx 21 \mathrm{~Gy}$ in children (treated with concomitant high-dose chemotherapy) to $\approx 43 \mathrm{~Gy}$ in adults [44,45]. Recently, a study suggested a $36 \mathrm{~Gy}$ threshold [7]. The evolution of RT protocols and new technologies will certainly lead to a revision of radiotoxicity data in the future.

\subsection{Immunotherapy}

Immune checkpoints function by maintaining immunological homeostasis through the inhibition of T-cell activation. Immune checkpoint inhibitor (ICI) actions lead to constitutive T-cell activation and anti-tumor activity; however, they are counterbalanced by a range of dysimmune toxicities grouped as immune-related adverse events (IRAEs) that can affect virtually any organ [13,46]. Skin toxicities, including maculopapular rash, eczema and vitiligo, are the most common IRAEs, affecting $\approx 40 \%$ of patients [46]. Notably, some of these skin conditions may lead to alopecia when they extend to the scalp. 
Currently, ICPI-induced alopecia (IIA) is estimated at $1-2 \%$, with a molecule-dependent variation [47]. In a recent meta-analysis focused on melanoma treatment, the following incidences of alopecia were found: $1.7 \%$ for ipilimumab, $2 \%$ for nivolumab and $3.4 \%$ for pembrolizumab [48]. According to the mechanism involved, namely direct or indirect, IIA can be classified as primary (IIA-P) or secondary (IIA-S), respectively.

IIA-P occurs when the reactivation of ICPIs directly leads to scalp dysimmunity. Mechanistically, IIA-P exhibits alopecia areata features; the hair follicle loses its immune privilege, with an intense perifollicular lymphocytic infiltration. Concerning onset kinetics, high variability has been described, from a few weeks to over a year [11]. Persistent IIA has already been described through case reports [49]. To date, treatment mainly involves class IV topical steroids or systemic immunosuppressants in recalcitrant cases [47]. Very interestingly, case reports proposed that IIA-P could be a predictive marker of nivolumab efficacy in melanoma [50]. Beyond IIA, changes in texture and hair repigmentation processes have also been described [46].

IIA-S should be observed in the context of IRAE, as one of its indirect consequences is alopecia. Therefore, it is necessary to rule out an underlying IIA-S before diagnosing an IIA-P. IIA-S management has to consider an etiologic therapy and to favor a multidisciplinary approach [51]. The most often identified IIA-S is through thyroid dysfunction; indeed, it is estimated that $\approx 10 \%$ of ICPI-treated patients will develop thyroid complications [46]. Emerging upon ICPI introduction, genuine autoimmune (e.g., systemic lupus erythematosus and scleroderma) and inflammatory (e.g., sarcoidosis-like and severe drug conditions) diseases have been reported, leading to secondary scarring alopecia [52].

\subsection{Other Mechanisms}

A certain number of mechanisms potently leading to alopecia are worth mentioning. The first one is cancer-induced malnutrition, affecting $30-50 \%$ of patients [53]. Moreover, hair renewal requires a sufficient vitamin/mineral/energy supply; for instance, vitamin (e.g., vitamin D) and/or micronutrient (e.g., iron and zinc) deficiencies can lead to alopecia [54]. Apart from these, alopecia may unravel an underlying cancer by two main mechanisms. Firstly, scalp metastases can exhibit alopecia features, the so-called alopecia neoplastica [55]. Secondly, a paraneoplastic mechanism can be the first clinical sign of cancer; several case reports of paraneoplastic alopecia have been described, notably through paraneoplastic dermatosis $[56,57]$. As previously described, alopecia has been described following allogeneic BMT via graft-versus-host disease [58].

\section{Alopecia Management}

To date, no curative treatment is indicated for ANIA; however, several studies have demonstrated some effectiveness of certain treatments. Global alopecia management (from prophylaxis to palliative approaches) is summarized in Table $6[10-13,59]$.

Importantly, although it is clearly out of the scope of this review, psychological alterations related to alopecia and their consequences on quality of life should not be overlooked $[7,20,25]$. 
Table 6. Currently issued recommendations for the management of ANIA based on the literature (adapted from references $[10-13,59])$.

\begin{tabular}{|c|c|c|}
\hline $\begin{array}{l}\text { Type of } \\
\text { Alopecia }\end{array}$ & Recommendation(s) & $\begin{array}{l}\text { Level of } \\
\text { Evidence }\end{array}$ \\
\hline $\begin{array}{l}\text { Global } \\
\text { approaches }\end{array}$ & $\begin{array}{l}\text { Hair status evaluation and differential diagnoses eviction } \\
\text { (anamnesis, clinical examination, biological assessment, } \\
\text { trichoscopy, trichogram, }+/- \text { biopsy) } \\
\text { - } \quad \text { Haircut before treatment initiation } \\
\text { - } \quad \text { Hair prosthesis and textile accessories } \\
\text { - } \quad \text { Camouflage techniques (e.g., pigmentation, keratin powder) } \\
\text { Early accompaniment (medical, paramedical, psychologist, } \\
\text { cancer support group) }\end{array}$ & \\
\hline CIA & $\begin{array}{l}\text { - } \quad \text { Prevention of hair loss: } \mathrm{eCC}^{*} \\
\text { - }\end{array}$ & $\begin{array}{l}\text { II } \\
\text { IV }\end{array}$ \\
\hline pCIA & $\begin{array}{ll}\text { - } & \text { TMX-5\% } \\
\text { - } & \text { Spironolactone (twice daily) } \\
* * *\end{array}$ & $\begin{array}{l}\text { IV } \\
\text { IV }\end{array}$ \\
\hline EIA & $\begin{array}{ll}\text { - } & \text { TMX-5\% ** (twice daily) } \\
\text { - } & \text { Spironolactone } * * *\end{array}$ & $\begin{array}{l}\text { III } \\
\text { IV }\end{array}$ \\
\hline RIA & - Acceleration of spontaneous regrowth: TMX $2-5 \%$ ** & IV \\
\hline pRIA & $\begin{array}{ll}\text { - } & \text { TMX-5\% ** (twice daily) } \\
\text { - } & \text { Surgery (e.g., hair graft, skin expansion) }\end{array}$ & $\begin{array}{l}\text { IV } \\
\text { IV }\end{array}$ \\
\hline IIA & - $\quad$ Class IV DC **** & IV \\
\hline TIA & $\begin{array}{l}\text { - } \quad \text { TMX-5\% ** (twice daily) } \\
\text { - } \quad \text { If inflammation is associated: DC }\end{array}$ & $\begin{array}{l}\text { IV } \\
\text { IV }\end{array}$ \\
\hline Eyebrows/Lashes & - $\quad$ Bimatoprost & III \\
\hline
\end{tabular}

Nota bene: some of these proposed treatments are under investigation and are not yet FDA approved; more detailed information is in the text. Abbreviations: $(\mathrm{p}) \mathrm{CIA}=$ (persistent) chemotherapy-induced alopecia; $\mathrm{DC}=$ dermocorticoids; $\mathrm{eCC}=$ electronic cooling cap; EIA = endocrine therapy-induced alopecia; IIA = immunotherapy-induced alopecia; (p)RIA = (persistent) radiotherapy-induced alopecia; TIA $=$ targeted therapy-induced alopecia; TMX = topical minoxidil. Addenda: ${ }^{*}$ Paxman $\odot$ and Dignicap $\odot$ scalp cooling systems are FDA approved; ** for women, only the foam type has FDA approval for AGA treatment, and for CIA/RIA, TMX should be used twice daily, during treatment protocol and up to 4 months after; ${ }^{* * *}$ in the context of a hormone-sensitive tumor, it requires particular supervision considering the theoretical risk of hormone stimulation; ${ }^{* * * *}$ treatment proposed for primary IIA.

\subsection{ANIA Prevention}

As the number of patients cured or in remission is constantly growing and with the move toward a patient-centered medicine, supportive care concerning ANIA appears essential [25,59].

Initial management, before any anticancer treatment, is hair status evaluation. Indeed, a pre-existing pathological condition (such as vitamin/mineral deficiency or a more general disorder) is likely to increase ANIA, either by a complementary mechanism or in synergy. Although there is no standard test currently recommended, the following minimum biological test should be performed when facing alopecia without an obvious etiology: complete blood count, [TSH], [vitamin D], [iron] + / - hormonal assays.

In the therapeutic arsenal, the cooling cap (CC) -with or without cooling mittens/socks in order to protect extremities-has been used empirically for several decades. CC is based on cooling the scalp during chemotherapy administration in order to provoke a local vasoconstriction and, thus, a lesser exposure of the hair follicles. Two techniques currently exist: $\mathrm{CC}$ filled with gel and kept cold ( $\mathrm{gCC}$, requiring a regular change of CC during the same cure) and electric CC (eCC, based on the circulation of a capillary cooling liquid through an automated, meanwhile more expensive, technique). CC was quickly considered relevant because of its non-invasiveness and its low cost, counterbalanced by a formal absence of proof of effectiveness and safety. Nevertheless, democratization of its use has been slowing down for a long time, considering the theoretical risk of scalp metastases, the multiplicity of care practices, protocols with a long IV infusion and patient acceptability [60]. Indeed, 
historical reports of a few cases of scalp metastases have been reported, leading to an initial precautionary principle. Since the 1980s, numerous exploratory studies have been performed, primarily in patients with BC; however, the lack of randomized clinical trials and the multiplicity of chemotherapy protocols and of ways to use CC led to limited data [61].

Meanwhile, two prospective clinical trials published in 2017 have shown the efficacy of eCC. The first one was a prospective multicenter cohort study of patients (106 using the DigniCap $\odot \mathrm{eCC}$ and 16 as controls) with localized $\mathrm{BC}$ and treated with adjuvant taxanebased chemotherapy and followed-up annually for 5 years. The primary outcome was whether the use of eCC was associated with ANIA prevention (defined as CTCAE grade $\leq 1$ alopecia, equivalent to hair loss $\leq 50 \%$ ): indeed, two-thirds of the patients in the eCC group had ANIA prevention versus $0 \%$ in the control group. Furthermore, the impact on QoL was also assessed: only one-quarter of patients felt "physically less attractive" in the eCC group versus $>50 \%$ in the control group [62]. The second study evaluated the efficacy of the PaxMan $\odot$ eCC on CIA in a multicenter randomized clinical trial, which enrolled 119 patients in the eCC group (versus 63 in the control group) with localized $\mathrm{BC}$ and treated with anthracyclines and/or taxanes. The primary endpoint was ANIA prevention (defined as CTCAE grade $\leq 1$ alopecia) after four cycles of chemotherapy. Hair preservation was found in $50 \%(\mathrm{CI} 95 \%=40.7-60.4 \%)$ of patients in the eCC group versus $0 \%$ $(\mathrm{C} 195 \%=0-7.6 \%)$ in the control group [63]. In addition, a meta-analysis (pooling 24 studies concerning BC patients) did not find an increased risk of scalp metastases with CC [64].

Furthermore, meta-analyses have shown that eCC exhibits more efficacy compared to other techniques available for ANIA prevention $[65,66]$. Importantly, CC is currently the only treatment validated by the FDA for CIA prophylaxis and could therefore represent an effective and safe tool for some chemotherapy protocols. However, due to the current dynamics of the ambulatory shift, chemotherapies given through a long IV infusion as well as those dispensed orally are not eligible for the use of CC [67].

\subsection{ANIA Treatments}

Topical minoxidil (TMX) is indicated in AGA in both genders. Recently, TMX-5\% has been demonstrated to be efficient in EIA $(n=46)$, with $80 \%$ of patients showing moderate to significant improvement within 3-6 months [8]. Furthermore, TMX-2\% has shown some efficacy after chemotherapy for hair regrowth (by reducing CIA from 137 days for placebo to 87 days), without an effect on CIA prevention [68]. In a cohort of patients with pRIA $(n=34)$, TMX-5\% exhibited some effect, with $12 \%$ complete response and $38 \%$ partial response rates [7].

Spironolactone (owing to its anti-androgenic effect) tends to be prescribed off-label for female AGA when accompanied by signs of hyperandrogenism. Since AGA and EIA share the same pathophysiology, spironolactone could represent an interesting treatment of EIA. Concerning its safety, a recent study has shown that spironolactone did not interact with ET and did not increase the risk of BC [69].

Bimatoprost (a synthetic prostaglandin analogue) is classically indicated as an eye drop for intraocular hypertonia. Since 2008, it is also indicated for ciliary hypotrichosis treatment. Several controlled clinical studies have shown bimatoprost gel efficacy for chemotherapy-induced ciliary hypotrichosis, reporting a faster regrowth and an increased density of treated lashes [70].

Hair autotransplantation (HAT), a surgery technique, consists of harvesting follicles from a donor area and then transplanting them into a recipient area in order to increase hair density; in the context of ANIA, the main limit is an insufficient follicular density of the donor area. Recently, it has been demonstrated that HAT could be a relevant treatment for EIA in women: interestingly, a single session was sufficient to recover a satisfying hairline in $70 \%$ of patients. In addition, a 3-year follow-up confirmed the persistence of the graft as well as its safety [71]. This technique could be extended to other ANIAs when the donor area is sufficient and when alopecia is considered stable. Finally, a skin expansion (by 
placing prostheses under the scalp and followed by plastic surgery) could be a promising surgical technique for pRIA/pCIA [72].

Regarding the therapeutic perspectives, various preclinical and clinical studies have reported the efficacy of molecules such as cyclosporine, topical vasoconstrictors and antioxidants [73]. However, large-scale transposition in humans has not yet demonstrated clinically significant efficacy. The Clinicaltrials.gov database currently references 15 active clinical studies for ANIA treatment [74]. For CIA, studies include CC $(n=10)$, keratinocyte growth factor $(n=1)$ and LED lights $(n=1)$. One study is currently evaluating the effect of platelet-rich plasma in EIA and pCIA. For pCIA, ongoing studies include oral minoxidil $(n=1)$ and $C C(n=1)$. In addition to new synthetic entities, interesting perspectives are cell therapy and in vitro neogenesis of hair follicles from autologous cells [75].

\subsection{Palliative Care and Supplementary Management}

Beyond the medical approach stricto sensu, it is important to remember that supportive care in oncology is essential through an early and multidisciplinary approach $[25,59]$. The use of wigs and turbans represents one of the current methods of dealing with established alopecia. Several types exist, using different hair-making technologies. Having an early haircut should be advised for limiting the putative change in self-perception induced by alopecia. For psychological concerns, referral to patient associations and psychological support should also be proposed, depending on the situation [4,5]. As the aesthetic aspect can play a major role in improving QoL, patients should be referred to nurses and socio-aestheticians specialized in these types of cares. The latter can propose different camouflage techniques, such as wigs/turbans, dermopigmentation and keratin powder. Dermopigmentation consists of tattooing micro-dots/-traits on the skin through a dermal injection of bioresorbable pigments, giving the illusion of an increased hair and eyebrow density. The treatment requires an average of 2-3 sessions for an optimal result, lasting $2-5$ years. Keratin powder is based on natural keratin attaching to the remaining hair via static electricity, allowing a dramatic but temporary gain in hair density $[20,25,59]$.

\section{Conclusions}

Alopecia, apart from being a well-known side effect of cancer treatments, can reveal a diverse panel of etiologies linked to the disease itself. As such, (bio)clinical investigation should be performed when facing (a risk of) alopecia in the context of cancer in order to offer proper management. ANIA management frequently involves pluridisciplinary management, with the need to assess psychological repercussions and the consequences on the quality of life of patients. Each class of cancer treatment exhibits its own characteristics, and ANIA should not be seen as a homogeneous concern. On the preventive side, $\mathrm{eCC}$ has been positioned as a potent tool. Although current treatments exhibit mild efficacy, several therapeutic approaches are under development.

Author Contributions: All authors participated equally to writing —original draft preparation and review and editing S.Q., A.G. and F.F. All authors have read and agreed to the published version of the manuscript.

Funding: The APC was funded by Centre hospitalier Universitaire de Nîmes.

Institutional Review Board Statement: Not applicable.

Informed Consent Statement: Not applicable.

Conflicts of Interest: Stanislas Quesada has no conflict of interest to declare. Alexandre Guichard is employed by Legacy Healthcare. Frédéric Fiteni has no conflict of interest to declare. None of the authors declare any relevant conflicts of interest involving the work under consideration for publication. 


\section{References}

1. Blume-Peytavi, U. (Ed.) Hair Growth and Disorders; Springer: Berlin/Heidelberg, Germany, 2008; ISBN 978-3-540-46908-7.

2. Cho, J.; Choi, E.K.; Kim, I.R.; Im, Y.H.; Park, Y.H.; Lee, S.; Lee, J.E.; Yang, J.H.; Nam, S.J. Development and Validation of Chemotherapy-Induced Alopecia Distress Scale (CADS) for Breast Cancer Patients. Ann. Oncol. Off. J. Eur. Soc. Med. Oncol. 2014, 25, 346-351. [CrossRef]

3. Macquart-Moulin, G.; Viens, P.; Palangié, T.; Bouscary, M.L.; Delozier, T.; Roché, H.; Janvier, M.; Fabbro, M.; Moatti, J.P. High-Dose Sequential Chemotherapy with Recombinant Granulocyte Colony-Stimulating Factor and Repeated Stem-Cell Support for Inflammatory Breast Cancer Patients: Does Impact on Quality of Life Jeopardize Feasibility and Acceptability of Treatment? J. Clin. Oncol. Off. J. Am. Soc. Clin. Oncol. 2000, 18, 754-764. [CrossRef]

4. Carelle, N.; Piotto, E.; Bellanger, A.; Germanaud, J.; Thuillier, A.; Khayat, D. Changing Patient Perceptions of the Side Effects of Cancer Chemotherapy. Cancer 2002, 95, 155-163. [CrossRef]

5. Mulders, M.; Vingerhoets, A.; Breed, W. The Impact of Cancer and Chemotherapy: Perceptual Similarities and Differences between Cancer Patients, Nurses and Physicians. Eur. J. Oncol. Nurs. Off. J. Eur. Oncol. Nurs. Soc. 2008, 12, 97-102. [CrossRef]

6. Kang, D.; Kim, I.-R.; Im, Y.H.; Park, Y.H.; Ahn, J.S.; Lee, J.E.; Nam, S.J.; Park, H.; Kim, E.; Lee, H.K.; et al. Quantitative Changes in Skin Composition Parameters Due to Chemotherapy in Breast Cancer Patients: A Cohort Study. Breast Cancer Res. Treat. 2015, 152, 675-682. [CrossRef]

7. $\quad$ Phillips, G.S.; Freret, M.E.; Friedman, D.N.; Trelles, S.; Kukoyi, O.; Freites-Martinez, A.; Unger, R.H.; Disa, J.J.; Wexler, L.H.; Tinkle, C.L.; et al. Assessment and Treatment Outcomes of Persistent Radiation-Induced Alopecia in Patients with Cancer. JAMA Dermatol. 2020, 156, 963. [CrossRef]

8. Freites-Martinez, A.; Shapiro, J.; Chan, D.; Fornier, M.; Modi, S.; Gajria, D.; Dusza, S.; Goldfarb, S.; Lacouture, M.E. Endocrine Therapy-Induced Alopecia in Patients with Breast Cancer. JAMA Dermatol. 2018, 154, 670-675. [CrossRef] [PubMed]

9. Saggar, V.; Wu, S.; Dickler, M.N.; Lacouture, M.E. Alopecia with Endocrine Therapies in Patients with Cancer. Oncologist 2013, 18, 1126-1134. [CrossRef]

10. Freites-Martinez, A.; Shapiro, J.; Goldfarb, S.; Nangia, J.; Jimenez, J.J.; Paus, R.; Lacouture, M.E. Hair Disorders in Patients with Cancer. J. Am. Acad. Dermatol. 2019, 80, 1179-1196. [CrossRef]

11. Freites-Martinez, A.; Shapiro, J.; van den Hurk, C.; Goldfarb, S.; Jimenez, J.J.; Rossi, A.M.; Paus, R.; Lacouture, M.E. Hair Disorders in Cancer Survivors. J. Am. Acad. Dermatol. 2019, 80, 1199-1213. [CrossRef]

12. Robert, C.; Sibaud, V.; Mateus, C.; Cherpelis, B.S. Advances in the Management of Cutaneous Toxicities of Targeted Therapies. Semin. Oncol. 2012, 39, 227-240. [CrossRef] [PubMed]

13. Lacouture, M.; Sibaud, V. Toxic Side Effects of Targeted Therapies and Immunotherapies Affecting the Skin, Oral Mucosa, Hair, and Nails. Am. J. Clin. Dermatol. 2018, 19, 31-39. [CrossRef]

14. Belum, V.R.; Marulanda, K.; Ensslin, C.; Gorcey, L.; Parikh, T.; Wu, S.; Busam, K.J.; Gerber, P.A.; Lacouture, M.E. Alopecia in Patients Treated with Molecularly Targeted Anticancer Therapies. Ann. Oncol. Off. J. Eur. Soc. Med. Oncol. 2015, 26, $2496-2502$. [CrossRef]

15. Humbert, P.; Fanian, F.; Maibach, H.I.; Agache, P. Agache's Measuring the Skin: Non-Invasive Investigations, Physiology, Normal Constants; Hair Trichogram; Guichard, A., Fanian, F., Eds.; Springer: Cham, Switzerland, 2016; pp. 801-812. ISBN 978-3-31932381-7.

16. Olsen, E.A. Chemotherapy-Induced Alopecia: Overview and Methodology for Characterizing Hair Changes and Regrowth. In The MASCC Textbook of Cancer Supportive Care and Survivorship; Olver, I., Ed.; Springer: New York, NY, USA, 2011; ISBN 978-1-4419-1224-4.

17. National Institutes of Health; National Cancer Institute. Common Terminology Criteria for Adverse Events (CTCAE), Version 5.0. November 2017. Available online: https://ctep.cancer.gov/protocoldevelopment/electronic_applications/docs/ctcae_v5_quick_ reference_5x7.pdf (accessed on 1 June 2021).

18. Fischer, T.W.; Schmidt, S.; Strauss, B.; Elsner, P. [Hairdex: A tool for evaluation of disease-specific quality of life in patients with hair diseases]. Der Hautarzt 2001, 52, 219-227. [CrossRef] [PubMed]

19. Bjelic-Radisic, V.; Cardoso, F.; Cameron, D.; Brain, E.; Kuljanic, K.; da Costa, R.A.; Conroy, T.; Inwald, E.C.; Serpentini, S.; Pinto, M.; et al. An International Update of the EORTC Questionnaire for Assessing Quality of Life in Breast Cancer Patients: EORTC QLQ-BR45. Ann. Oncol. Off. J. Eur. Soc. Med. Oncol. 2020, 31, 283-288. [CrossRef]

20. Freites-Martinez, A.; Chan, D.; Sibaud, V.; Shapiro, J.; Fabbrocini, G.; Tosti, A.; Cho, J.; Goldfarb, S.; Modi, S.; Gajria, D.; et al. Assessment of Quality of Life and Treatment Outcomes of Patients with Persistent Postchemotherapy Alopecia. JAMA Dermatol. 2019, 155, 724-728. [CrossRef] [PubMed]

21. Paus, R.; Haslam, I.S.; Sharov, A.A.; Botchkarev, V.A. Pathobiology of Chemotherapy-Induced Hair Loss. Lancet Oncol. 2013, 14, e50-e59. [CrossRef]

22. Trüeb, R.M. Chemotherapy-Induced Anagen Effluvium: Diffuse or Patterned? Dermatology 2007, 215, 1-2. [CrossRef] [PubMed]

23. Rzepecki, A.K.; Cheng, H.; McLellan, B.N. Cutaneous Toxicity as a Predictive Biomarker for Clinical Outcome in Patients Receiving Anticancer Therapy. J. Am. Acad. Dermatol. 2018, 79, 545-555. [CrossRef]

24. Chung, S.; Low, S.-K.; Zembutsu, H.; Takahashi, A.; Kubo, M.; Sasa, M.; Nakamura, Y. A Genome-Wide Association Study of Chemotherapy-Induced Alopecia in Breast Cancer Patients. Breast Cancer Res. BCR 2013, 15, R81. [CrossRef] 
25. Tallon, B.; Blanchard, E.; Goldberg, L.J. Permanent Chemotherapy-Induced Alopecia: Case Report and Review of the Literature. J. Am. Acad. Dermatol. 2010, 63, 333-336. [CrossRef]

26. Baker, B.W.; Wilson, C.L.; Davis, A.L.; Spearing, R.L.; Hart, D.N.; Heaton, D.C.; Beard, M.E. Busulphan/Cyclophosphamide Conditioning for Bone Marrow Transplantation May Lead to Failure of Hair Regrowth. Bone Marrow Transplant. 1991, 7, $43-47$.

27. Prevezas, C.; Matard, B.; Pinquier, L.; Reygagne, P. Irreversible and Severe Alopecia Following Docetaxel or Paclitaxel Cytotoxic Therapy for Breast Cancer. Br. J. Dermatol. 2009, 160, 883-885. [CrossRef] [PubMed]

28. Stoehr, J.R.; Kosche, C.; Choi, J.N. Permanent Chemotherapy-Induced Alopecia: Awareness and Attitudes among Health Care Providers. Support. Care Cancer Off. J. Multinatl. Assoc. Support. Care Cancer 2020, 28, 2887-2890. [CrossRef]

29. Kang, D.; Kim, I.-R.; Choi, E.-K.; Im, Y.H.; Park, Y.H.; Ahn, J.S.; Lee, J.E.; Nam, S.J.; Lee, H.K.; Park, J.-H.; et al. Permanent Chemotherapy-Induced Alopecia in Patients with Breast Cancer: A 3-Year Prospective Cohort Study. Oncologist 2019, 24, 414-420. [CrossRef] [PubMed]

30. Kluger, N.; Jacot, W.; Frouin, E.; Rigau, V.; Poujol, S.; Dereure, O.; Guillot, B.; Romieu, G.; Bessis, D. Permanent Scalp Alopecia Related to Breast Cancer Chemotherapy by Sequential Fluorouracil/Epirubicin/Cyclophosphamide (FEC) and Docetaxel: A Prospective Study of 20 Patients. Ann. Oncol. Off. J. Eur. Soc. Med. Oncol. 2012, 23, 2879-2884. [CrossRef]

31. Núñez-Torres, R.; Martín, M.; García-Sáenz, J.Á.; Rodrigo-Faus, M.; del Monte-Millán, M.; Tejera-Pérez, H.; Pita, G.; de la TorreMontero, J.C.; Pinilla, K.; Herraez, B.; et al. Association Between ABCB1 Genetic Variants and Persistent Chemotherapy-Induced Alopecia in Women with Breast Cancer. JAMA Dermatol. 2020, 156, 987-991. [CrossRef]

32. Bresters, D.; Wanders, D.C.M.; Louwerens, M.; Ball, L.M.; Fiocco, M.; van Doorn, R. Permanent Diffuse Alopecia after Haematopoietic Stem Cell Transplantation in Childhood. Bone Marrow Transplant. 2017, 52, 984-988. [CrossRef] [PubMed]

33. Xie, P.; Lefrançois, P. Efficacy, Safety, and Comparison of Sonic Hedgehog Inhibitors in Basal Cell Carcinomas: A Systematic Review and Meta-Analysis. J. Am. Acad. Dermatol. 2018, 79, 1089-1100. [CrossRef]

34. Alkeraye, S.; Maire, C.; Desmedt, E.; Templier, C.; Mortier, L. Persistent Alopecia Induced by Vismodegib. Br. J. Dermatol. 2015, 172, 1671-1672. [CrossRef]

35. Peng, C.; Lei, J.-X. The Incidence and Risk of Cutaneous Toxicities Associated with Dabrafenib in Melanoma Patients: A Systematic Review and Meta-Analysis. Eur. J. Hosp. Pharm. Sci. Pract. 2020. [CrossRef] [PubMed]

36. Agulnik, M.; Yarber, J.L.; Okuno, S.H.; von Mehren, M.; Jovanovic, B.D.; Brockstein, B.E.; Evens, A.M.; Benjamin, R.S. An OpenLabel, Multicenter, Phase II Study of Bevacizumab for the Treatment of Angiosarcoma and Epithelioid Hemangioendotheliomas. Ann. Oncol. Off. J. Eur. Soc. Med. Oncol. 2013, 24, 257-263. [CrossRef]

37. Mir-Bonafé, J.F.; Saceda-Corralo, D.; Vañó-Galván, S. Adverse Hair Reactions to New Targeted Therapies for Cancer. Actas Dermo-Sifiliográficas 2019, 110, 182-192. [CrossRef]

38. Gallicchio, L.; Calhoun, C.; Helzlsouer, K.J. Aromatase Inhibitor Therapy and Hair Loss among Breast Cancer Survivors. Breast Cancer Res. Treat. 2013, 142, 435-443. [CrossRef]

39. Puglisi, F.; Aprile, G.; Sobrero, A. Tamoxifen-Induced Total Alopecia. Ann. Intern. Med. 2001, 134, 1154-1155. [CrossRef]

40. Moscetti, L.; Agnese Fabbri, M.; Sperduti, I.; Fabrizio, N.; Frittelli, P.; Massari, A.; Pompei, L.; D'Auria, G.; Pofi, E.; Ruggeri, E.M. Adjuvant Aromatase Inhibitor Therapy in Early Breast Cancer: What Factors Lead Patients to Discontinue Treatment? Tumori 2015, 101, 469-473. [CrossRef] [PubMed]

41. Lasheen, S.; Shohdy, K.S.; Kassem, L.; Abdel-Rahman, O. Fatigue, Alopecia and Stomatitis among Patients with Breast Cancer Receiving Cyclin-Dependent Kinase 4 and 6 Inhibitors: A Systematic Review and Meta-Analysis. Expert Rev. Anticancer Ther. 2017, 17, 851-856. [CrossRef] [PubMed]

42. Sonke, G.S.; Hart, L.L.; Campone, M.; Erdkamp, F.; Janni, W.; Verma, S.; Villanueva, C.; Jakobsen, E.; Alba, E.; Wist, E.; et al. Ribociclib with Letrozole vs Letrozole Alone in Elderly Patients with Hormone Receptor-Positive, HER2-Negative Breast Cancer in the Randomized MONALEESA-2 Trial. Breast Cancer Res. Treat. 2018, 167, 659-669. [CrossRef]

43. Halperin, E.C. Perez E Brady's Principles and Practice of Radiation Oncology; Wolters Kluwer: Philadelphia, PA, USA, 2019; ISBN 978-1-4963-8679-3.

44. Lawenda, B.D.; Gagne, H.M.; Gierga, D.P.; Niemierko, A.; Wong, W.M.; Tarbell, N.J.; Chen, G.T.Y.; Hochberg, F.H.; Loeffler, J.S. Permanent Alopecia after Cranial Irradiation: Dose-Response Relationship. Int. J. Radiat. Oncol. 2004, 60, 879-887. [CrossRef]

45. Min, C.H.; Paganetti, H.; Winey, B.A.; Adams, J.; MacDonald, S.M.; Tarbell, N.J.; Yock, T.I. Evaluation of Permanent Alopecia in Pediatric Medulloblastoma Patients Treated with Proton Radiation. Radiat. Oncol. 2014, 9, 220. [CrossRef]

46. Martins, F.; Sofiya, L.; Sykiotis, G.P.; Lamine, F.; Maillard, M.; Fraga, M.; Shabafrouz, K.; Ribi, C.; Cairoli, A.; Guex-Crosier, Y.; et al. Adverse Effects of Immune-Checkpoint Inhibitors: Epidemiology, Management and Surveillance. Nat. Rev. Clin. Oncol. 2019, 16, 563-580. [CrossRef] [PubMed]

47. Zarbo, A.; Belum, V.R.; Sibaud, V.; Oudard, S.; Postow, M.A.; Hsieh, J.J.; Motzer, R.J.; Busam, K.J.; Lacouture, M.E. ImmuneRelated Alopecia (Areata and Universalis) in Cancer Patients Receiving Immune Checkpoint Inhibitors. Br. J. Dermatol. 2017, 176, 1649-1652. [CrossRef]

48. Almutairi, A.R.; McBride, A.; Slack, M.; Erstad, B.L.; Abraham, I. Potential Immune-Related Adverse Events Associated with Monotherapy and Combination Therapy of Ipilimumab, Nivolumab, and Pembrolizumab for Advanced Melanoma: A Systematic Review and Meta-Analysis. Front. Oncol. 2020, 10, 91. [CrossRef] [PubMed]

49. Antoury, L.; Maloney, N.J.; Bach, D.Q.; Goh, C.; Cheng, K. Alopecia Areata as an Immune-Related Adverse Event of Immune Checkpoint Inhibitors: A Review. Dermatol. Ther. 2020, 33, e14171. [CrossRef] [PubMed] 
50. Lakhmiri, M.; Cavelier-Balloy, B.; Lacoste, C.; Cassius, C.; Baroudjian, B.; Delyon, J.; Lebbé, C.; Reygagne, P. Nivolumab-Induced Alopecia Areata: A Reversible Factor of Good Prognosis? JAAD Case Rep. 2018, 4, 761-765. [CrossRef] [PubMed]

51. Simonaggio, A.; Michot, J.M.; Voisin, A.L.; Le Pavec, J.; Collins, M.; Lallart, A.; Cengizalp, G.; Vozy, A.; Laparra, A.; Varga, A.; et al. Evaluation of Readministration of Immune Checkpoint Inhibitors After Immune-Related Adverse Events in Patients with Cancer. JAMA Oncol. 2019. [CrossRef]

52. Sibaud, V. Dermatologic Reactions to Immune Checkpoint Inhibitors: Skin Toxicities and Immunotherapy. Am. J. Clin. Dermatol. 2018, 19, 345-361. [CrossRef]

53. Senesse, P.; Bachmann, P.; Bensadoun, R.J.; Besnard, I.; Bourdel-Marchasson, I.; Bouteloup, C.; Crenn, P.; Goldwasser, F.; Guérin, O.; Latino-Martel, P.; et al. Nutrition chez le patient adulte atteint de cancer: Textes courts. Nutrition Clinique et Métabolisme 2012, 26, 151-158. [CrossRef]

54. Guo, E.L.; Katta, R. Diet and Hair Loss: Effects of Nutrient Deficiency and Supplement Use. Dermatol. Pract. Concept. 2017, 1-10. [CrossRef] [PubMed]

55. Kim, J.-H.; Kim, M.-J.; Sim, W.-Y.; Lew, B.-L. Alopecia Neoplastica Due to Gastric Adenocarcinoma Metastasis to the Scalp, Presenting as Alopecia: A Case Report and Literature Review. Ann. Dermatol. 2014, 26, 624-627. [CrossRef]

56. Antoniou, E.; Paraskeva, P.; Smyrnis, A.; Konstantopoulos, K. Alopecia: A Common Paraneoplastic Manifestation of Cholangiocarcinoma in Humans and Animals. Case Rep. 2012, 2012, bcr2012006217. [CrossRef] [PubMed]

57. Qiao, J.; Zhou, G.; Ding, Y.; Zhu, D.; Fang, H. Multiple Paraneoplastic Syndromes: Myasthenia Gravis, Vitiligo, Alopecia Areata, and Oral Lichen Planus Associated with Thymoma. J. Neurol. Sci. 2011, 308, 177-179. [CrossRef]

58. Čeović, R.; Desnica, L.; Pulanić, D.; Serventi Seiwerth, R.; Ilić, I.; Grce, M.; Mravak Stipetić, M.; Klepac Pulanić, T.; Bilić, E.; Bilić, E.; et al. High Frequency of Cutaneous Manifestations Including Vitiligo and Alopecia Areata in a Prospective Cohort of Patients with Chronic Graft-vs-Host Disease. Croat. Med. J. 2016, 57, 229-238. [CrossRef] [PubMed]

59. Lacouture, M.E.; Sibaud, V.; Gerber, P.A.; van den Hurk, C.; Fernández-Peñas, P.; Santini, D.; Jahn, F.; Jordan, K. Prevention and Management of Dermatological Toxicities Related to Anticancer Agents: ESMO Clinical Practice Guidelines. Ann. Oncol. 2020, 32, 157-170. [CrossRef] [PubMed]

60. Betticher, D.C.; Delmore, G.; Breitenstein, U.; Anchisi, S.; Zimmerli-Schwab, B.; Müller, A.; von Moos, R.; Hügli-Dayer, A.M.; Schefer, H.; Bodenmann, S.; et al. Efficacy and Tolerability of Two Scalp Cooling Systems for the Prevention of Alopecia Associated with Docetaxel Treatment. Support. Care Cancer Off. J. Multinatl. Assoc. Support. Care Cancer 2013, 21, 2565-2573. [CrossRef]

61. Ross, M.; Fischer-Cartlidge, E. Scalp Cooling: A Literature Review of Efficacy, Safety, and Tolerability for Chemotherapy-Induced Alopecia. Clin. J. Oncol. Nurs. 2017, 21, 226-233. [CrossRef]

62. Rugo, H.S.; Klein, P.; Melin, S.A.; Hurvitz, S.A.; Melisko, M.E.; Moore, A.; Park, G.; Mitchel, J.; Bågeman, E.; D’Agostino, R.B.; et al. Association Between Use of a Scalp Cooling Device and Alopecia After Chemotherapy for Breast Cancer. JAMA 2017, $317,606$. [CrossRef]

63. Nangia, J.; Wang, T.; Osborne, C.; Niravath, P.; Otte, K.; Papish, S.; Holmes, F.; Abraham, J.; Lacouture, M.; Courtright, J.; et al. Effect of a Scalp Cooling Device on Alopecia in Women Undergoing Chemotherapy for Breast Cancer: The SCALP Randomized Clinical Trial. JAMA 2017, 317, 596-605. [CrossRef] [PubMed]

64. Rugo, H.S.; Melin, S.A.; Voigt, J. Scalp Cooling with Adjuvant/Neoadjuvant Chemotherapy for Breast Cancer and the Risk of Scalp Metastases: Systematic Review and Meta-Analysis. Breast Cancer Res. Treat. 2017, 163, 199-205. [CrossRef]

65. Rugo, H.S.; Voigt, J. Scalp Hypothermia for Preventing Alopecia During Chemotherapy. A Systematic Review and Meta-Analysis of Randomized Controlled Trials. Clin. Breast Cancer 2018, 18, 19-28. [CrossRef]

66. Zhou, T.; Han, S.; Zhu, Z.; Hu, Y.; Xing, W. Interventions for Preventing Chemotherapy-Induced Alopecia: A Systematic Review and Network Meta-Analysis of Randomized Controlled Trials. Cancer Nurs. 2020. [CrossRef]

67. Silva, G.D.B.; Ciccolini, K.; Donati, A.; Hurk, C.V.D. Scalp Cooling to Prevent Chemotherapy-Induced Alopecia. An. Bras. Dermatol. 2020, 95, 631-637. [CrossRef] [PubMed]

68. Duvic, M.; Lemak, N.A.; Valero, V.; Hymes, S.R.; Farmer, K.L.; Hortobagyi, G.N.; Trancik, R.J.; Bandstra, B.A.; Compton, L.D. A Randomized Trial of Minoxidil in Chemotherapy-Induced Alopecia. J. Am. Acad. Dermatol. 1996, 35, 74-78. [CrossRef] [PubMed]

69. Rozner, R.N.; Freites-Martinez, A.; Shapiro, J.; Geer, E.B.; Goldfarb, S.; Lacouture, M. Safety of $5 \alpha$-Reductase Inhibitors and Spironolactone in Breast Cancer Patients Receiving Endocrine Therapies. Breast Cancer Res. Treat. 2019, 174, 15-26. [CrossRef]

70. Barrón-Hernández, Y.L.; Tosti, A. Bimatoprost for the Treatment of Eyelash, Eyebrow and Scalp Alopecia. Expert Opin. Investig. Drugs 2017, 26, 515-522. [CrossRef] [PubMed]

71. Bouhanna, P.; Larif, M.; Guichard, A. Hair Transplantation in Endocrine Therapy-Induced Alopecia. Dermatol. Surg. 2020. publish ahead of print. [CrossRef] [PubMed]

72. Rannan-Eliya, Y.F.; Rannan-Eliya, S.; Graham, K.; Pizer, B.; McDowell, H.P. Surgical Interventions for the Treatment of RadiationInduced Alopecia in Pediatric Practice. Pediatr. Blood Cancer 2007, 49, 731-736. [CrossRef]

73. Dunnill, C.J.; Al-Tameemi, W.; Collett, A.; Haslam, I.S.; Georgopoulos, N.T. A Clinical and Biological Guide for Understanding Chemotherapy-Induced Alopecia and Its Prevention. Oncologist 2018, 23, 84-96. [CrossRef]

74. Clinicaltrials.Gov. Database. Available online: https: / clinicaltrials.gov/ct2/results?cond=Cancer+Alopecia\&term=\&cntry= \&state $=\&$ city $=\&$ dist $=($ accessed on 1 June 2021$)$.

75. Castro, A.R.; Logarinho, E. Tissue Engineering Strategies for Human Hair Follicle Regeneration: How Far from a Hairy Goal? Stem Cells Transl. Med. 2020, 9, 342-350. [CrossRef] 